\title{
PCSK9 regulates neuronal apoptosis by adjusting ApoER2 levels and signaling
}

\author{
Kai Kysenius $\cdot$ Pranuthi Muggalla $\cdot$ \\ Kert Mätlik · Urmas Arumäe · Henri J. Huttunen
}

Received: 28 October 2011/Revised: 5 March 2012/Accepted: 22 March 2012/Published online: 6 April 2012

(C) Springer Basel AG 2012

\begin{abstract}
The secreted protease proprotein convertase subtilisin/kexin type 9 (PCSK9) binds to low-density lipid (LDL) receptor family members LDLR, very low density lipoprotein receptor (VLDLR) and apolipoprotein receptor 2 (ApoER2), and promotes their degradation in intracellular acidic compartments. In the liver, LDLR is a major controller of blood LDL levels, whereas VLDLR and ApoER2 in the brain mediate Reelin signaling, a critical pathway for proper development of the nervous system. Expression level of PCSK9 in the brain is highest in the cerebellum during perinatal development, but is also increased in the adult brain after ischemia. The mechanism of PCSK9 function and its involvement in neuronal apoptosis is poorly understood. We show here that RNAimediated knockdown of PCSK9 significantly reduced the death of potassium-deprived cerebellar granule neurons (CGN), as shown by reduced levels of nuclear phosphorylated c-Jun and activated caspase-3, as well as condensed apoptotic nuclei. ApoER2 protein levels were increased in PCSK9 RNAi cells. Knockdown of ApoER2 but not of VLDLR was sufficient to reverse the protection provided by PCSK9 RNAi, suggesting that proapoptotic signaling of PCSK9 is mediated by altered ApoER2 function. Pharmacological inhibition of signaling pathways associated
\end{abstract}

Electronic supplementary material The online version of this article (doi:10.1007/s00018-012-0977-6) contains supplementary material, which is available to authorized users.

K. Kysenius · P. Muggalla $\cdot$ H. J. Huttunen $(\bowtie)$

Neuroscience Center, University of Helsinki, Viikinkaari 4,

P.O. Box 56, 00014 Helsinki, Finland

e-mail: Henri.Huttunen@helsinki.fi

K. Mätlik · U. Arumäe

Institute of Biotechnology, University of Helsinki,

Helsinki, Finland with lipoprotein receptors suggested that PCSK9 regulates neuronal apoptosis independently of NMDA receptor function but in concert with ERK and JNK signaling pathways. PCSK9 RNAi also reduced staurosporineinduced CGN apoptosis and axonal degeneration in the nerve growth factor-deprived dorsal root ganglion neurons. We conclude that PCSK9 potentiates neuronal apoptosis via modulation of ApoER2 levels and related anti-apoptotic signaling pathways.

Keywords Apoptosis - Neuron - ApoER2 - VLDLR . PCSK9 $\cdot$ JNK
Abbreviations
AD Alzheimer's disease
ApoE Apolipoprotein E
ApoER2 Apolipoprotein receptor 2
CGN Cerebellar granule neuron
Dab1 Disabled-1
DRGN Dorsal root ganglion neuron
ERK Extracellular-regulated kinase
HUVEC Human umbilical vein endothelial cell
IF Immunofluorescence
JNK c-Jun N-terminal kinase
LDL Low density lipid
LDLR Low density lipoprotein receptor
MAPK Mitogen-activated protein kinase
NF- $\kappa \mathrm{B} \quad$ Nuclear factor kappa-light-chain-enhancer of activated B cells
NGF Nerve growth factor
NMDA $\quad N$-Methyl-D-aspartate
PC Proprotein convertase
PCSK9 Proprotein convertase subtilisin/kexin type 9
PI3K Phosphatidylinositol 3-kinase 
RNAi RNA interference

SFK Src family kinase

shRNA Short hairpin RNA

STS Staurosporine

VLDLR Very low density lipoprotein receptor

WB Western blot

Wrt Wortmannin

\section{Introduction}

Neuronal apoptosis is crucial for proper development of the nervous system, and after neuronal trauma, proapoptotic mechanisms cause damage to neuronal network integrity [1]. Proprotein convertase subtilisin/kexin type 9 (PCSK9) is a member of the subtilisin family of proprotein convertases (PCs) [2], with an established role in the systemic control of blood cholesterol and a lesser-characterized role in neuronal development and apoptosis [3, 4]. Unlike the other PCs, the proteolytic function of PCSK9 is autoinhibited by non-covalent binding of the pro-domain to the catalytic site [5]. PCSK9 binds to the extracellular EGF-A repeat of low-density lipid receptor family members lowdensity lipoprotein receptor (LDLR), very low-density lipoprotein receptor (VLDLR), and apolipoprotein receptor-2 (ApoER2) [6, 7], and targets them for degradation in the intracellular acidic compartments [8]. Gain- and loss-of-function mutants of PCSK9 are associated with hyper- and hypocholesterolemia, respectively, by affecting systemic levels of LDLR and cholesterol uptake [9]. There are controversial data whether PCSK9 also regulates the levels of ApoER2 and VLDLR in vivo possibly affecting a wide range of neuronal functions [7, 10, 11]. In neurons, VLDLR and ApoER2 are involved in multiple cell signaling cascades through several extra- and intracellular binding partners including Reelin, apolipoprotein $\mathrm{E}$ (ApoE), disabled-1 (Dab1) and c-Jun N-terminal kinase (JNK) interacting proteins 1/2 (JIP1/2) among others (reviewed in [12]). Reelin and ApoE bind to and activate ApoER2 and VLDLR, controlling cortical and cerebellar development [13, 14], promoting cell survival [15], and regulating $N$-methyl-D-aspartic acid (NMDA) receptor activity through phosphorylation [16, 17]. Recently, it has been shown that PCSK9 reduces LDLR levels in mouse brain in vivo during development and after ischemic stroke [11], but the effect on ApoER2 and VLDLR remains unexplored.

The cerebellum displays strong expression of PCSK9, VLDLR and ApoER2, but little expression of LDLR [18] during postnatal development, coinciding with the developmental elimination of cerebellar granule neurons (CGN). The knockdown of both VLDLR and ApoER2 cause a
Reeler-phenotype in mice, resulting in neuronal lamination defects in both the cortex and cerebellum [13]. Proprotein convertase subtilisin/kexin type 9 has also been shown to play a role in neuronal development [18]. In zebrafish, PCSK9 knockdown causes a severe disorganization of the CNS resulting in prenatal death [18]. However, gene targeting of PCSK9 in mice results in lowered circulating lipoprotein and cholesterol levels with no gross effects on CNS development [19], similar to the phenotype observed in human populations with PCSK9 loss-of-function mutations [20].

The role of PCSK9 in neuronal apoptosis has been investigated in CGN cultures, where the transient expression of PCSK9 and its various mutants caused apoptosis partially reversible by caspase inhibitors [4]. A recent study showed that PCSK9 is also involved in human umbilical vein endothelial cell (HUVEC) apoptosis through modulation of the intrinsic apoptotic pathway, and that knockdown of endogenous PCSK9 provides protection from apoptosis as shown by reduced caspase activity [21]. The exact mechanism of PCSK9 action in mediating apoptosis is yet to be resolved.

In our studies, we used lentiviral delivery of short hairpin RNA (shRNA) to knock down the endogenous expression of PCSK9 in murine CGN prior to apoptosis induction by withdrawal of potassium, a well-characterized model of developmental neuronal apoptosis [22]. Proprotein convertase subtilisin/kexin type 9 RNA interference (RNAi) increased the viability of CGN and reduced the extent of apoptosis, as quantitated by markers of apoptotic cell death: cleaved caspase-3 and nuclear condensation. The activation of c-Jun was also significantly diminished in PCSK9 RNAi CGN, suggesting the involvement of the JNK pathway. The protected cells also exhibited higher levels of ApoER2 post-deprivation with little effect on VLDLR levels, indicating a possible role for ApoER2 receptor signaling in PCSK9-dependent apoptosis. RNAi of ApoER2 was sufficient to reverse the protection mediated by PCSK9 RNAi. Pharmacological analysis revealed that NMDA receptor function, a known target of ApoER2 signaling, is not required for anti-apoptotic effects of PCSK9 RNAi. Instead, extracellular-regulated kinase (ERK) and JNK signaling pathways act in cooperation with PCSK9 to regulate c-Jun and caspase-3 activation during activity-dependent CGN apoptosis. Similar anti-apoptotic effects were also observed in staurosporine (STS)-induced CGN cell death model and nerve growth factor (NGF) deprivation of dorsal root ganglia (DRG) neurons. We conclude that PCSK9 regulates neuronal apoptosis through modulation of ApoER2 levels and related signaling pathways that control the activation of c-Jun and caspase-3, key factors that ultimately determine the onset of apoptosis in neurons. 


\section{Materials and methods}

Stable HEK-293/mPCSK9-Fc cell line production

HEK-293 cells were cultured in Dulbecco's modified eagle medium (DMEM) supplemented with $10 \%$ FBS, $2 \mathrm{mM}$ L-glutamine, $1 \%$ penicillin, and $1 \%$ streptomycin. Murine PCSK9 (mPCSK9) was cloned into the pIG (+) plasmid (R\&D Systems) in-frame with a C-terminal Fc tag. pIG (+)-mPCSK9 was transfected to HEK-293 cells and stable cell lines were selected using G418. Single cell clones were generated and selected based on expression of mPCSK9-Fc using anti-human Fc antibody (Dako P214, 1:5,000).

RNAi and lentivirus production

Short hairpin RNA clones from the TRC-Mm1.0 (Mouse) library were acquired from OpenBiosystems (Thermo Fisher Scientific). Short hairpin RNAs were expressed from lentiviral pLKO.1 plasmid under the CMV promoter. Five shRNA clones targeting PCSK9 (clones TRCN00000327 84-G1, TRCN0000032785-G2, TRCN0000032786-G3, TRCN0000032787-F11, TRCN0000032788-F12), $\overline{\mathrm{Ap}}-$ oER2 (clones TRCN0000176508, TRCN0000177833, TR CN0000178706, TRCN0000176636, TRCN0000177656), VLDLR (clones TRCN0000127069, TRCN0000127070, TRCN0000127071, TRCN0000127072, TRCN0000127 073), and a single control shRNA were used in this study. Lentiviral particles were produced from the selected clones, and an additional mPCSK9-Fc overexpression plasmid, by cotransfection of the selected plasmids together with the envelope plasmid pMD2.G and the packaging plasmid pPAX2 into human embryonic kidney cells (HEK293T) using Fugene HD (Sigma) transfection reagent. After $48 \mathrm{~h}$ post-transfection, the supernatant containing the viral particles was collected, cleared by centrifugation, and concentrated for use in transduction of cultured neurons. After viral harvest, the cells were eradicated according to viral safety regulations.

\section{RT-PCR}

Primers were designed in Geneious software and synthesized by oligomer (Helsinki, Finland) for assessment of mPCSK9, VLDLR, ApoER2, and GAPDH mRNA. The oligos used were: mPCSK9 (forward) 5'-CTGCTCCA GAGGTCATCACAGTC-3'; (reverse) 5'-CAGGGAACCA GGCCATGTTGATG-3'; VLDLR (forward) 5'-GTGCAG CTGGGTTTGAACTGATAGATAGG-3'; (reverse) $5^{\prime}$-GT CTTAGAAGCCGCATCAGTCCAGTAG- $3^{\prime} ; \quad$ ApoER2 (forward) $5^{\prime}$-GACGAGGACGACTGCCCCAA- ${ }^{\prime}$; (reverse) $5^{\prime}$-GTCCCATCCCCACACTGGAACTC- ${ }^{\prime}$; GAPDH (forward) 5'-ACCCCTTCATTGACCTCAACTACATGG-3'; (reverse) 5'-ATCCACAGTCTTCTGGGTGGCA-3'. RNA was extracted from cell lysates by RNeasy RNA extraction kit (Qiagen) as described in the manual. cDNA synthesis was done using dT-oligos with the Finnzymes Dynazyme cDNA synthesis kit (F470) immediately after RNA extraction or after storage of the RNA samples in $-80^{\circ} \mathrm{C}$. PCR reactions were performed using Dynazyme II DNA polymerase. Samples run on the agarose gel were imaged by AlphaImager HP system.

Cerebellar granule neuron cultures and lentiviral transduction

Cerebellar granule neurons were prepared from P6 to P8 NMRI-mice. Mice were euthanized by decapitation, and the brain removed and placed in cold dissection buffer, composed of PBS supplemented with $0.25 \%$ glucose, $0.3 \%$ bovine serum albumin (BSA), $0.038 \% \mathrm{MgSO}_{4}$. Cerebella were cleaned and trypsinized in $10 \mathrm{ml}$ of dissection buffer containing $0.025 \%$ trypsin for $15 \mathrm{~min}$ in a $37{ }^{\circ} \mathrm{C}$ waterbath with occasional inversion. Prewarmed dissection buffer containing $10 \%$ fetal bovine serum (FBS) and $12 \mu \mathrm{g} / \mathrm{ml}$ DNase I was added for DNA digestion and trypsin inactivation. Cells were washed in dissection buffer containing $0.012 \% \mathrm{CaCl}_{2}$, counted and plated on poly-L-lysine (Sigma)-coated cell culture plates at a density of 1-1.5 million cells per well in 6-well plates. Each well also included one sterile and poly-L-lysine coated $9 \mathrm{~mm}$ coverslip for immunofluorescence (IF) staining. Cells were resuspended and grown in neurobasal medium (Gibco) supplemented with $2 \%$ B27, $2 \mathrm{mM}$ L-glutamine, $1 \%$ penicillin/streptomycin, $0.5 \% \mathrm{FBS}$ and $25 \mathrm{mM} \mathrm{KCl}$. Half of the media was changed at 1 day(s) in vitro (DIV) and at 3-4 DIV prior to lentiviral transduction. Cerebellar granule neurons were transduced at 3-4 DIV and cultured for 72-96 h prior to treatments.

Dorsal root ganglion dissection, culture and NGF deprivation

Dorsal root ganglia (DRG) were collected from E15 NMRI mice and treated with $1.25 \mathrm{mg} / \mathrm{ml}$ trypsin (Worthington) in HBSS for $30 \mathrm{~min}$ at $37^{\circ} \mathrm{C}$. Then, the ganglia were washed twice with HBSS and treated with DNase I $(40 \mu \mathrm{g} / \mathrm{ml})$ in the presence of $3 \mathrm{mM} \mathrm{MgCl} 2$ in HBSS for $5 \mathrm{~min}$ at $37{ }^{\circ} \mathrm{C}$. The DRG were washed with HBSS once and dissociated by trituration, using a silicone-treated Pasteur pipette. The cells were pelleted by centrifugation, resuspended in DMEM, $5 \%$ FBS, and $1 \%$ penicillin/streptomycin, and plated on an uncoated cell-culture dish for $5 \mathrm{~h}$ at $37{ }^{\circ} \mathrm{C}$, in $5 \% \mathrm{CO}_{2}$ to reduce the number of non-neuronal cells, which attach to uncoated plastic. The medium, enriched with dorsal root ganglion neurons (DRGN), was then collected, the cells pelleted by centrifugation and resuspended 
in neurobasal medium, supplemented with $2 \%$ B-27, $0.2 \%$ Primocin and $20 \mathrm{ng} / \mathrm{ml} \mathrm{NGF}$ (Promega). The cells were plated in a drop of medium to MatTek cell-culture dishes previously coated with $1 \mathrm{mg} / \mathrm{ml}$ poly-L-ornithine (Sigma) diluted in $0.15 \mathrm{M}$ borate buffer $\mathrm{pH}$ 8.7, and $40 \mathrm{ug} /$ $\mathrm{ml}$ Laminin (Sigma) diluted in HBSS. More of the same medium was added next morning to cover the whole dish. Half of the medium was changed at least $2 \mathrm{~h}$ before lentiviral transduction at 10 DIV. Dorsal root ganglion neurons were transduced for $72 \mathrm{~h}$ prior to NGF deprivation at 13 DIV. For NGF deprivation, cells were washed twice with plain Neurobasal, and $1 \mathrm{ml}$ of neurobasal supplemented with $2 \%$ B-27, $1 \%$ penicillin, $1 \%$ streptomycin, and $0.5 \mu \mathrm{g} / \mathrm{ml}$ anti-NGF antibody (Millipore) was added to cells for $24 \mathrm{~h}$. Cells were fixed using $4 \%$ PFA, the axons stained with anti- $\beta$-III-tubulin (TUJ1) antibody and imaged using a confocal microscope (Carl Zeiss LSM 5). Axons were quantitated from microscope images by counting the number of intact axons showing no blebbing or fragmentation crossing the diagonal of the image.

\section{CGN treatments}

Cerebellar granule neuron deprivations were performed in 6-7 DIV cultures. Cells were washed twice with plain neurobasal and neurobasal with $0.5 \%$ FBS, $1 \%$ penicillin/ streptomycin, $2 \mathrm{mM}$ L-glutamine and $5 \mathrm{mM} \mathrm{KCl}$ concentration was used to deprive the cells. For pharmacological inhibition, cells were pre-treated with inhibitors for $30 \mathrm{~min}$ and equal concentration of inhibitors was added to the deprivation media. Deprivation was stopped by the collection of the conditioned media and cell lysate. Staurosporine (500 nM; Sigma) induced apoptosis was assessed after 6 or $24 \mathrm{~h}$. The inhibitors used were wortmannin (100 nM; Sigma), U0126 (10 $\mu \mathrm{M}$; Sigma), SP600125 (4 $\mu \mathrm{M}$; Sigma), Sulfasalazine (125 $\mu \mathrm{M}$; Santa Cruz), and PP2 ( $8 \mu \mathrm{M}$; Santa Cruz). NMDAR antagonists AP5 (Sigma) and MK-801 (Sigma) were used at concentrations of 50 and $0.5 \mu \mathrm{M}$, respectively.

\section{Protein samples and western blotting}

The cell lysate collection procedure was done on ice. Protein lysates were scraped in extraction buffer containing $10 \mathrm{mM}$ Tris-HCl, pH 7.6, $2 \mathrm{mM}$ EDTA, $0.15 \mathrm{M} \mathrm{NaCl}$, $1 \%$ Triton-X, inhibitor cocktail (1 pill/10 ml; Roche), and $0.25 \%$ NP-40 (Sigma). Lysates were incubated for $30 \mathrm{~min}$ on ice and cleared by centrifugation at $10,000 \mathrm{~g}$ for $10 \mathrm{~min}$. Lysate concentrations were measured with BCA protein concentration kit (Pierce) and equal protein amounts (20-40 $\mu$ g per lane) were loaded on the gel. Samples were denatured for $10 \mathrm{~min}$ at $70{ }^{\circ} \mathrm{C}$ and reduced with $1 \%$ $\beta$-mercaptoethanol (BME) in the $10 \mu \mathrm{l}$ of $4 \times$ loading buffer
(Invitrogen) added to each sample. The gel apparatus (X-Cell SureLock ${ }^{\mathrm{TM}}$; Invitrogen) was assembled with NuPAGE 4-12\% 10-well Bis-Tris gels (Invitrogen) immersed in running buffer (Invitrogen). Protein ladders from Bio-Rad (Precision Plus Kaleidoscope, 161-0375) and Invitrogen (Novex Sharp Pre-Stained, LC5800) were used as standards for protein size assessment. Gels were run at $160 \mathrm{~V}$ for $60 \mathrm{~min}$ with a Bio-Rad power source. Prior to semi-dry blotting (Semi-Dry Trans-Blot SD; Bio-Rad), the gel and the PVDF protein membrane (Amersham HybondP) were pre-soaked in the transfer buffer $(48 \mathrm{mM}$ Tris, $39 \mathrm{mM}$ glycine, $13 \mathrm{mM}$ SDS, $200 \mathrm{ml}$ methanol, and 11 of reverse osmosis water) for $15 \mathrm{~min}$. Proteins were transferred to the membrane at $20 \mathrm{~V}$ for $30 \mathrm{~min}$.

Immunodetection

Membranes were blocked in $5 \%$ non-fat milk powder (Valio) diluted in TBST [TBS $+0.1 \%$ Tween-20 (Sigma)] for $1 \mathrm{~h}$ on a gyro-rocker (Stuart, SLL3) at room temperature (RT). Membranes were washed with plain TBST $3 \times 10 \mathrm{~min}$ before addition of primary antibody $(1 \mathrm{Ab})$ for overnight incubation at $4{ }^{\circ} \mathrm{C}$ on a rocker. Primary antibodies used were: cleaved caspase-3 (Cell Signaling; rabbit, 1:1,000), $\beta$-tubulin I + II (Sigma; mouse, 1:1,000), phospho-c-Jun (Cell Signaling; rabbit, 1:1,000), ApoER2 (Sigma; rabbit, 1:2,000), VLDLR (Santa Cruz; rabbit, 1:500), and GAPDH (Millipore; mouse, 1:1,000). After overnight $1 \mathrm{Ab}$ incubation, membranes were washed three times 10 min with TBST and appropriate secondary antibody ( $2 \mathrm{Ab}$ ) was added for $1 \mathrm{~h}$ on the gyro-rocker at RT. Horseradish peroxidase-linked anti-mouse (GE Healthcare) and anti-rabbit (GE Healthcare) secondary antibodies were used at a 1:6,000 dilution in TBST. Membranes were washed $3 \times 10 \mathrm{~min}$ with TBST and then soaked for $3 \mathrm{~min}$ with Pierce ECL reagent (Thermo Scientific). Protein bands were detected with LAS-3000 imaging system (Fujifilm). Quantity One ${ }^{\circledR}$ software (Bio-Rad) was used for optical density quantitation of western blots. Membranes were reprobed with several antibodies and stripped between probings. Membrane stripping was done at $55^{\circ} \mathrm{C}$ for $20 \mathrm{~min}$ in stripping buffer $(20 \mathrm{ml} 3 \mathrm{M}$ Tris- $\mathrm{HCl} \mathrm{pH}$ $6.8,100 \mathrm{ml} 20 \%$ SDS, $0.75 \% \beta$-mercaptoethanol). The membranes were then washed $3 \times 15$ min with TBST before another cycle of blocking $-1 \mathrm{Ab}-2 \mathrm{Ab}-$ detection.

Immunofluorescence imaging

Cells grown on poly-L-lysine coated coverslips were fixed for 20 min with $4 \%$ PFA in PBS. Cells were washed three times with PBS before adding blocking buffer [5\% normal serum (goat and/or donkey), $1 \%$ BSA, $0.1 \%$ gelatin, $0.1 \%$ Triton-X, $0.05 \%$ Tween-20] for $1 \mathrm{~h}$ at RT. Primary 
antibodies were added into dilution buffer (1\% BSA, $0.1 \%$ gelatin) and incubated overnight at $+4{ }^{\circ} \mathrm{C}$. Cells were washed three times with PBS and secondary antibodies diluted into PBS were added for $1 \mathrm{~h}$ in RT protected from light. Cells were washed twice with PBS and cells stained with Hoechst $(1: 10,000)$ for $10 \mathrm{~min}$ at RT. Cells were washed twice with PBS and once with milli-Q water to remove excess salts. Coverslips were mounted on microscope slides with ProLong anti-fade reagent (Invitrogen) and sealed with nail polish. The primary antibodies used were Tuj1 (Covance; rabbit, 1:500), MAP2 (Sigma; mouse, 1:500) and phospho-c-Jun (Cell Signaling; rabbit, 1:250). Secondary antibodies used were AlexaFluor-conjugated antibodies (Invitrogen) 488-goat-anti-mouse, 488-donkeyanti-rabbit, 568-goat-anti-mouse and 568-donkey-anti-rabbit at 1:2,000 dilutions. ImageJ software was used for cell counting and GraphPad Prism and Adobe Photoshop for preparation of figures.

\section{Statistical analyses}

Minimum of three repetitions from at least two different batches of cells were analyzed for each experiment. Microsoft Excel and GraphPad Prism software were used for statistical analyses. Statistical significance was evaluated with Student's $t$ test or ANOVA, with the significance threshold set at $p<0.05$.

\section{Results}

PCSK9 RNAi inhibits caspase-3 and c-Jun activation in potassium deprived CGN

We used lentiviral RNAi to reduce the endogenous expression of PCSK9 to assess its role in potassium (K5) deprivation-induced apoptosis in murine CGN, a wellcharacterized neuronal apoptosis model [23]. Replacing the depolarizing $25 \mathrm{mM} \mathrm{KCl-containing} \mathrm{medium} \mathrm{with} 5 \mathrm{mM}$ $\mathrm{KCl}$ medium results in a rapid apoptotic death of CGN mimicking the developmental elimination of cerebellar neurons $[24,25]$. The point-of-no-return for the CGN apoptosis takes place within the first $6 \mathrm{~h}$ of deprivation, and the onset of apoptosis can be observed at $6 \mathrm{~h}$ postdeprivation by phosphorylation of c-Jun, the central transcription factor required for JNK-dependent apoptosis, and activation of caspase-3, a major executioner of apoptosis $[22,26,27]$. Although an increase in PCSK9 expression coincides with CGN apoptosis, its role in the process is currently poorly understood [4].

Five PCSK9 RNAi target sequences were tested by transfection in a stable HEK-293/mPCSK9-Fc cell line to validate the constructs. The PCSK9 RNAi constructs G2 and F12 showed the best knockdown efficacy as analyzed by western blotting (WB) (Fig. 1a). Lentiviral particles were prepared and tested by cotransduction with mPCSK9Fc. G2 lentivirus was chosen for following PCSK9 RNAi experiments for its best efficacy in reducing the levels of co-transduced mPCSK9-Fc in CGN (Fig. 1b). The knockdown effect of PCSK9 RNAi on endogenous mPCSK9 in CGN was verified by RT-PCR (Fig. 1c, d). We detected a significant increase in the endogenous PCSK9 mRNA levels in non-transduced (control) CGN following K5 deprivation that was significantly attenuated by PCSK9 RNAi (Fig. 1d). The CGN were cultured in the absence of cytosine arabinoside or other DNA synthesis blockers that are used in many CGN protocols to prevent glial proliferation, as it was observed that these compounds significantly inhibited lentiviral transduction efficiency (data not shown). Nevertheless, the CGN cultured in Neurobasal (NB) supplemented with $2 \%$ B27 and $0.5 \%$ FBS contained a homogenous population of neurons $(>95 \%)$ (data not shown).

We then assessed the effect of PCSK9 RNAi on the apoptosis induced by $\mathrm{K} 5$ deprivation. We found that PCSK9 RNAi reduced the activation of phospho-c-Jun and caspase- 3 as quantitated by WB (Fig. 1e-h) after 6 h K5 deprivation. An additional PCSK9 RNAi construct (F12) and a non-target control shRNA sequence (Ctrl shRNA) were included to control for the possible off-target effects resulting from lentiviral RNAi. PCSK9 RNAi constructs $\mathrm{G} 2$ and $\mathrm{F} 12$ reduced caspase- 3 activity by $58.7 \pm 4.8$ and $44.0 \pm 5.3 \%$ respectively; and phospho-c-Jun activity by $44.4 \pm 11.5$ and $44.5 \pm 10.2 \%$, respectively, whereas Ctrl shRNA only slightly increased their respective activities in comparison to the control cells (Fig. 1g, h).

Phosphorylation of c-Jun and caspase-3 cleavage precede apoptosis and are inhibited by PCSK9 RNAi

The extent of antiapoptotic effects elicited by PCSK9 RNAi were assessed by K5 deprivations at 2, 4, 6, 9, and $24 \mathrm{~h}$ and evaluated by apoptotic markers with both WB and immunofluorescence (IF) imaging (Fig. 2). Western blotting analysis showed a significant increase in phosphoc-Jun of control cells already at $2 \mathrm{~h}$ post-deprivation peaking at roughly $4 \mathrm{~h}$ post-deprivation with the activation sustained up through $9 \mathrm{~h}$ post-deprivation (Fig. 2a, c). Cleavage of caspase- 3 was significantly increased by $4 \mathrm{~h}$ post-deprivation in control cells and reached its peak between 6 and $9 \mathrm{~h}$ post-deprivation (Fig. 2a, d). PCSK9 RNAi cells followed the same kinetics, but their respective activation levels were significantly lower at all timepoints, c-Jun activation peaking at $63.1 \pm 18.2 \%$ at $4 \mathrm{~h}$ and caspase- 3 activation peacking at $42.4 \pm 5.7 \%$ at $6 \mathrm{~h}$ postdeprivation (Fig. 2b-d). 
Fig. 1 Lentiviral PCSK9 RNAi reduces endogenous PCSK9 levels and the activation of phospho-c-Jun and caspase- 3 in murine CGN following potassium deprivation. a Validation of the PCSK9 RNAi constructs in HEK-293/ mPCSK9-Fc stable cell line using Fc-antibody. The last parts of the complete TRC clone names (see "Materials and methods" for details) are used to differentiate between clones. b PCSK9 RNAi clone G2 inhibits the overexpression of mPCSK9-Fc after cotransduction of overexpression and RNAi. c The levels of endogenous PCSK9 mRNA in CGN. Overexpression vector is used as a positive control (lane 1). d Quantitation of mRNA levels of endogenous PCSK9 mRNA in CGN after RNAi. The level of PCSK9 mRNA is reduced and the rise in mRNA levels caused by $6 \mathrm{~h} \mathrm{~K} 5$ deprivation is blocked by PCSK9 RNAi. e-h PCSK9 RNAi clones $\mathrm{G} 2$ and $\mathrm{F} 12$ reduce phospho-c-Jun and caspase-3 activation after 6-hour deprivation when compared to Ctrl shRNA or non-transduced (control) cells. PCSK9 RNAi construct F12 and Ctrl shRNA construct are included to assess for the specificity and non-target effects of lentiviral RNAi. Data are shown as mean \pm SEM of three or more replicate experiments. In $(\mathbf{d}, \mathbf{g}, \mathbf{h})$, $* * p<0.01, * * * p<0.001$ a

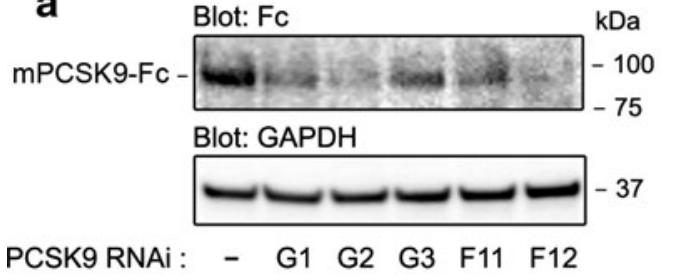

C

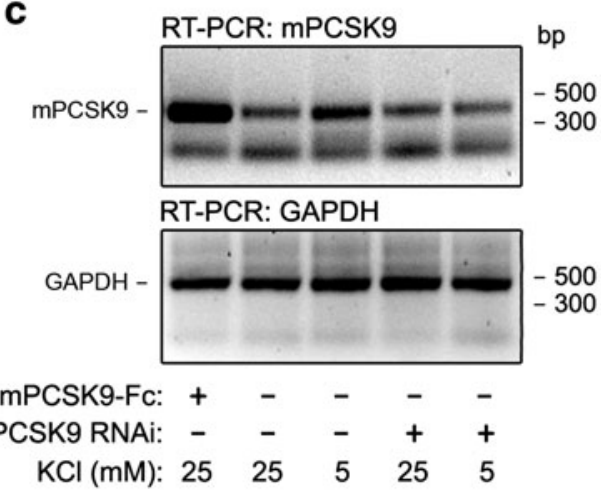

e

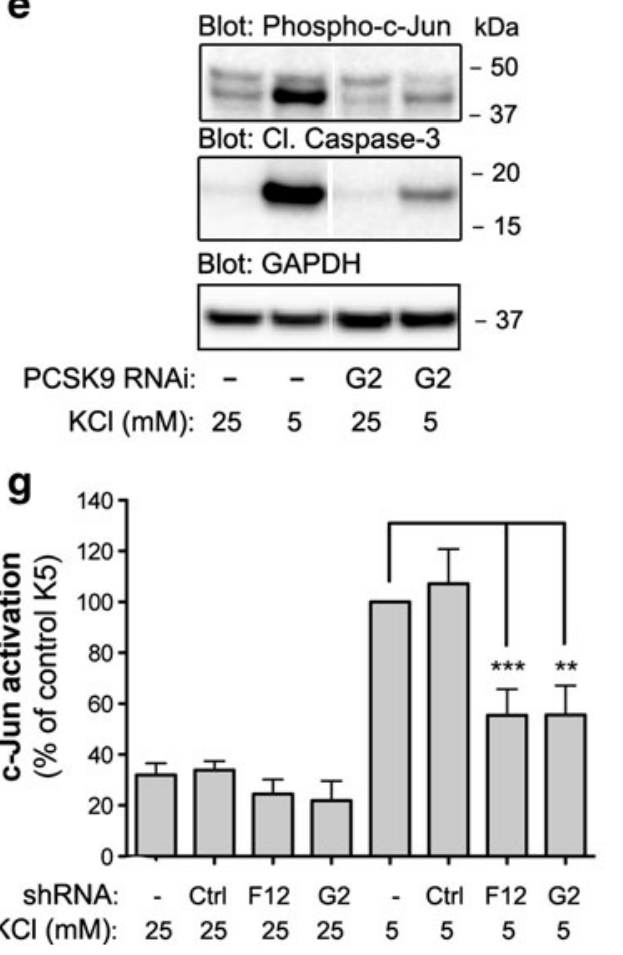

b

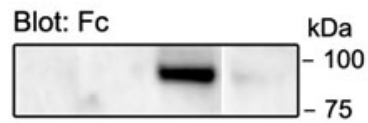

Blot: GAPDH

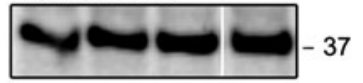

mPCSK9-Fc: $-\quad++$

PCSK9 RNAi: -+++

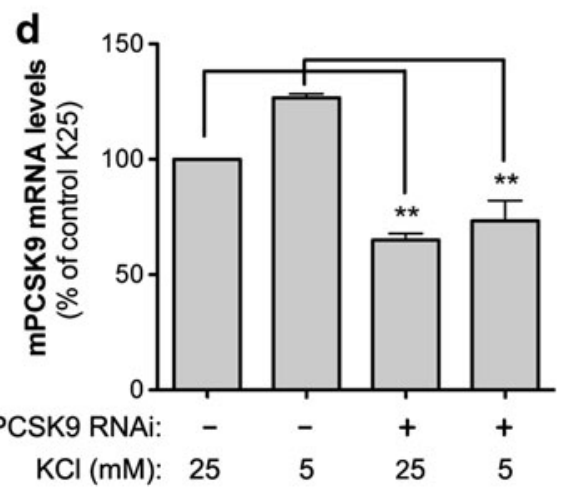

f

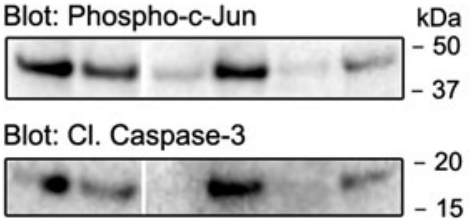

Blot: GAPDH

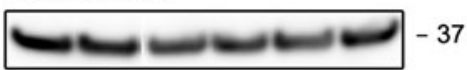

shRNA: - G2 Ctrl Ctrl F12 F12

$\mathrm{KCl}(\mathrm{mM}): 5 \quad 5 \quad 25 \quad 5 \quad 25 \quad 5$

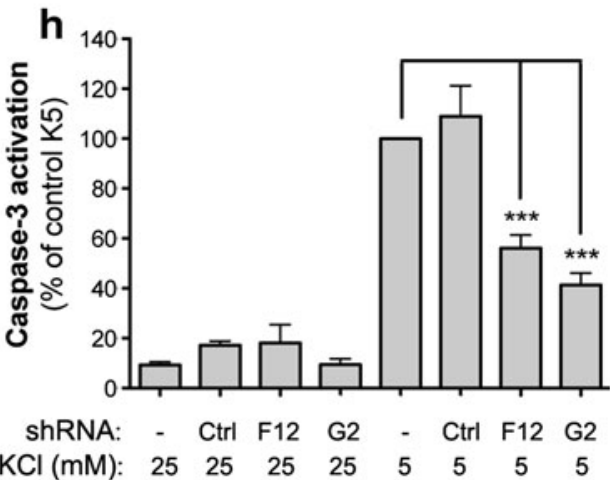

Similar results were obtained by microscopic quantitation of phospho-c-Jun positive cells and apoptotic nuclei (Fig. 2e-h). PCSK9 RNAi cells showed both increased cell viability and decreased number of phospho-c-Jun positive cells at timepoints ranging from 4 to $24 \mathrm{~h}$ and 0 to $9 \mathrm{~h}$, respectively (Fig. $2 \mathrm{~g}$, h). Immunofluorescence imaging of CGN showed that active phospho-c-Jun colocalizes with the cell nuclei and precedes nuclear condensation (Fig. 2f). Cell nuclei were scored according to their morphology and phospho-c-Jun positivity (Fig. 2g, h). In control K5 cells,
$79.9 \pm 2.1 \%$ of healthy nuclei showing no signs of condensation or fragmentation were phospho-c-Jun positive, compared to PCSK9 RNAi cells, which showed only $39.1 \pm 5.4 \%$ positivity at $6 \mathrm{~h} \mathrm{~K} 5$, without a significant increase to control cells cultured in K25 (Fig. 2g). The basal level of phospho-c-Jun positivity in K25 cells was also decreased by PCSK9 RNAi (Fig. 2e, g). While the total number of neurons present in the culture did not significantly differ between the groups (data not shown), after $6 \mathrm{~h}$ K5 deprivation, $33.6 \pm 3.1 \%$ of control cells 
a

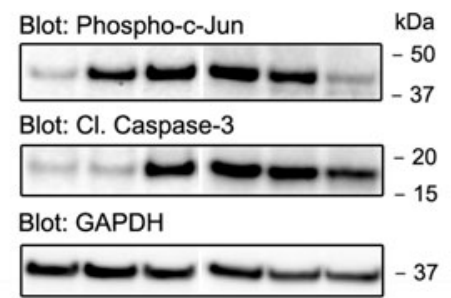

Deprivation (h): $\quad \begin{array}{llllll}0 & 2 & 4 & 6 & 9 & 24\end{array}$

C

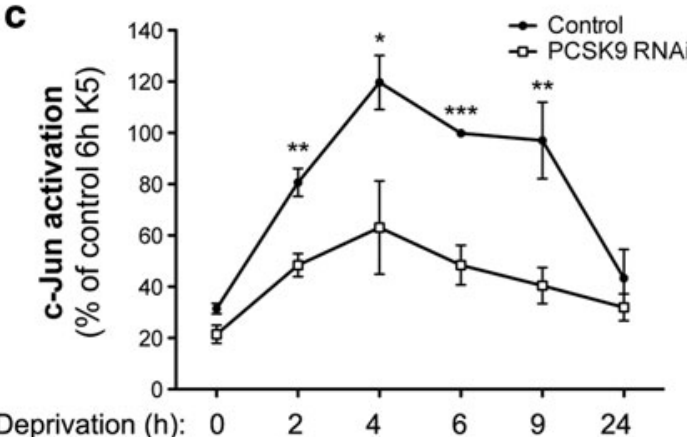

e
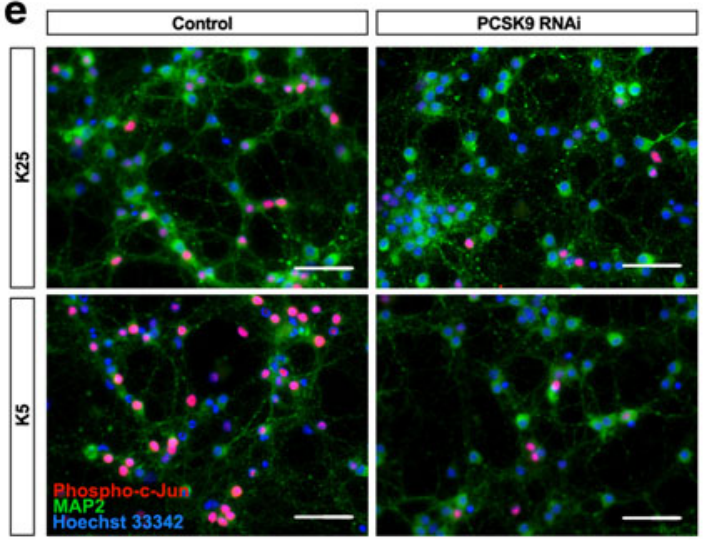

f

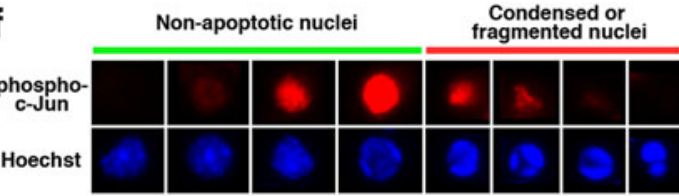

Fig. 2 CGN viability is increased and activation of c-Jun and caspase-3 lowered by PCSK9 RNAi at timepoints up to $24 \mathrm{~h}$ postdeprivation. a, b Western blot analysis of untransduced control (a) and PCSK9 RNAi CGN (b) showing the activation of phospho-cJun and caspase- 3 at timepoints $0,2,4,6,9$ and $24 \mathrm{~h}$ post-deprivation. Sample load was controlled by GAPDH staining. c, d Percentage of c-Jun and caspase-3 activation (control $6 \mathrm{~h} \mathrm{K5}$ set at $100 \%$ ) quantitated from Western blots (a, b) and normalized to GAPDH levels. e Representative immunofluorescence images showing dendrites (MAP2, green), nuclear phospho-c-Jun (phospho-c-Jun, red) and nuclei (Hoechst 33342, blue) of control and PCSK9 RNAi CGN

showed apoptotic nuclear morphology but only $19.9 \pm 2.4 \%$ of PCSK9 RNAi K5 cells were apoptotic, a reduction of $41 \%$ (Fig. 2h). The protective effect of b

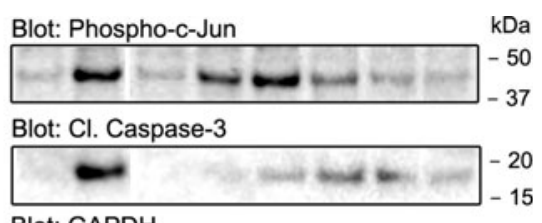

Blot: GAPDH

Deprivation (h): $\begin{array}{llllllll}0 & 6 & 0 & 2 & 4 & 6 & 9 & 24\end{array}$

PCSK9 RNAi: - - + + + + + +

d

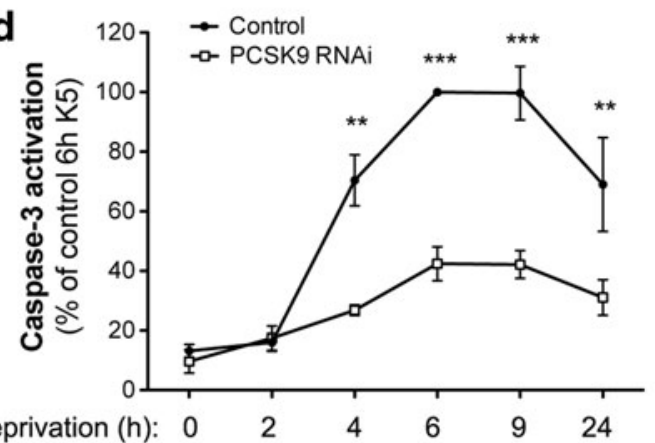

Deprivation (h): $\begin{array}{lllllll}0 & 2 & 4 & 6 & 9 & 24\end{array}$

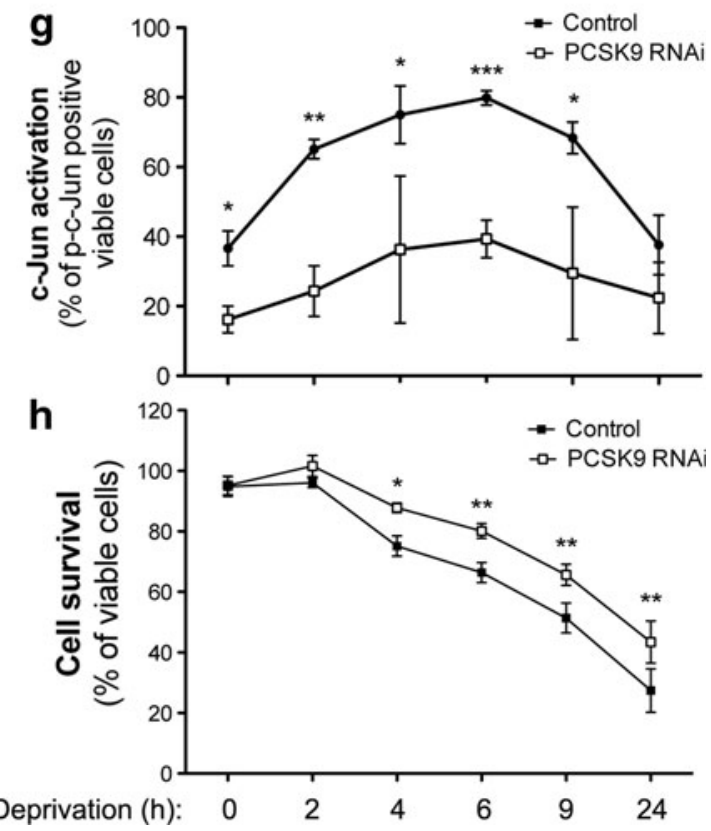

before (K25) and after (K5) $6 \mathrm{~h}$ potassium/serum deprivation. Scale bars $50 \mu \mathrm{m}$. f Comparison of activated nuclear phospho-c-Jun (red) and nuclear (blue) morphological changes occurring during cell death caused by potassium deprivation. $\mathbf{g}$, $\mathbf{h}$ Analysis of immunofluorescence staining (representative images shown in panel $e$ ) at timepoints $0,2,4,6,9$, and $24 \mathrm{~h}$ post-deprivation. More than 300 cells/timepoint/ sample were analyzed from three separate experiments to assess phospho-c-Jun positivity (g) and cell survival by nuclear morphology (h). Data are shown as mean \pm SEM of three or more replicate experiments. In (c, d, $\mathbf{g}, \mathbf{h}),{ }^{*} p<0.05, * * p<0.01,{ }^{* * *} p<0.001$

PCSK9 RNAi was still seen at $24 \mathrm{~h}$ post-deprivation, as only $27.4 \pm 7.2 \%$ of control cells were viable compared to the $43.4 \pm 6.9 \%$ of viable PCSK9 RNAi cells (Fig. 2h). 
However, even in the PCSK9 RNAi, CGN survival was reduced by $24 \mathrm{~h}$, possibly due to activation of other, nonapoptotic cell death pathways [28].

Reduction of active c-Jun suggests that PCSK9 RNAi mediates its protective effect by modulating the JNKpathway upstream of c-Jun and caspase-3 activation, which are known effectors of potassium deprivation in CGN. Also, the basal level of c-Jun activation was lowered in K25 PCSK9 RNAi cells (Fig. 2b, e, g). Altogether, these findings show that PCSK9 RNAi is neuroprotective against K5 deprivation-induced apoptosis in CGN and that this process involves modulation of c-Jun activation.

Cells protected by PCSK9 RNAi exhibit altered levels of lipoprotein receptors VLDLR and ApoER2

The lipoprotein receptors ApoER2 and VLDLR can activate pro-survival signaling through the inactivation of the JNK-pathway and by increasing PI3K and ERK1/2 activity [29]. Proprotein convertase subtilisin/kexin type 9 has the ability to bind and degrade ApoER2 and VLDLR [7]. A recent study has shown that PCSK9 can enhance degradation of VLDLR in adipose tissue in vivo [30], although it is controversial whether this happens in the brain in vivo $[7,11]$. Cerebellar granule neurons endogenously express ApoER2 and VLDLR and their levels are significantly reduced following K5 deprivation (Fig. 3a-d). However, the basal levels of ApoER2 in PCSK9 RNAi cells were increased by $41.3 \pm 5.6 \%$ while VLDLR levels were not significantly altered in comparison to control cells (Fig. 3b-d). Moreover, ApoER2 levels remained elevated above basal control levels in PCSK9 RNAi cells until $9 \mathrm{~h}$ post-deprivation, despite their gradual decline (Fig. 3b, d).

To study the role of ApoER2 and VLDLR in the neuronal survival further, we produced lentiviral RNAi against both receptors. Efficiency of VLDLR and ApoER2 RNAi was quantitated by WB and RT-PCR (Suppl. Fig. 1). This also validated the specificity of the VLDLR and ApoER2 antibodies used in this study. Two RNAi constructs displaying ability to decrease lipoprotein receptor levels were chosen and their effects were assessed in PCSK9 RNAitreated CGN undergoing 6 h K5 deprivation. Importantly, the knockdown of ApoER2 alone (or both of the receptors) simultaneously with PCSK9 RNAi was able to completely reverse the protection elicited by PCSK9 RNAi, as assessed by caspase-3 activation (Fig. 3e, f). Very low density lipoprotein receptor RNAi alone did not have any reversal effect, although it should be noted that the efficacy of the VLDLR RNAi was somewhat weaker as compared to ApoER2 RNAi (Suppl. Fig. 1).

Very low density lipoprotein receptor is located in the fluid, phospholipid-rich regions of the membrane and is primarily involved in the internalization of lipoprotein particles consisting of ApoE and other lipoproteins as well as Reelin. In comparison, ApoER2 is mostly located in lipid-rafts and functions primarily in cell signaling and as a scaffold for intracellular adaptor molecules [12]. Apolipoprotein receptor 2 has been shown to regulate neuronal survival in the brain via a JNK-dependent mechanism involving the adaptor molecule JIP1/2, suggesting a possible mechanism for PCSK9 RNAi-mediated protection [15]. Therefore, increased levels of ApoER2 are likely the key contributor to the anti-apoptotic effects of PCSK9 RNAi.

NMDA receptor activity is not required for the anti-apoptotic effects of PCSK9 RNAi

Very low density lipoprotein receptor and ApoER2dependent Reelin and ApoE signaling activates Dab1 and Src-family kinases (SFKs) to modulate NMDA receptor function and long-term potentiation (LTP) in neurons [31]. NMDA receptor activation is associated with both survival and cell death, depending on the extent of receptor activation and $\mathrm{Ca}^{2+}$ currents generated [32]. Pre-treatment with subtoxic levels of NMDA has been shown to inhibit apoptosis-associated JNK activation in CGN [33]. We next assessed the possible role of lipoprotein receptor-dependent NMDA receptor modulation in PCSK9 RNAi mediated neuroprotection. We used competitive and noncompetitive antagonists AP5 and MK-801, respectively, to block NMDA receptors 30 min prior to and during K5 deprivation before the evaluation of caspase- 3 activation. We observed no effect in the extent of caspase- 3 activation in either the control or PCSK9 RNAi cells (Fig. 4a).

Src family kinases are important downstream effectors of neuronal ApoER2/VLDLR signaling, and can enhance NMDA receptor activity via subunit tyrosine phosphorylation [17, 34]. PP2, a selective inhibitor of SFKs, had no effect on anti-apoptotic effects of PCSK9 RNAi as measured by caspase- 3 activation at $6 \mathrm{~h}$ post-deprivation (Fig. 4b). Therefore, we conclude that NMDAR modulation is not mechanistically involved in PCSK9 RNAi neuroprotection, at least in this CGN model.

Pharmacological profiling of neuroprotection elicited by PCSK9 RNAi

In order to dissect potential pathways associated with PCSK9 RNAi-mediated neuroprotection, we assessed the involvement of selected intracellular signaling routes, previously linked with ApoER2/VLDLR signaling or potassium deprivation-induced CGN apoptosis, in the antiapoptotic effects of PCSK9 RNAi by pharmacological modulation. We used inhibitors wortmannin (Wrt), U0126, SP600125 and sulfasalazine (SFS) to block 
a

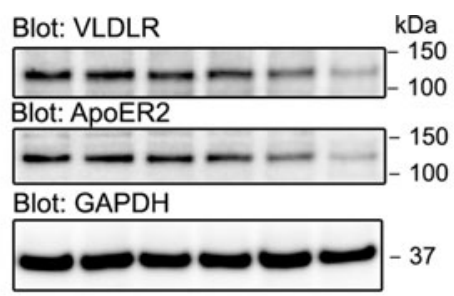

Deprivation (h): $0 \quad \begin{array}{llllll}0 & 2 & 4 & 6 & 9 & 24\end{array}$

C

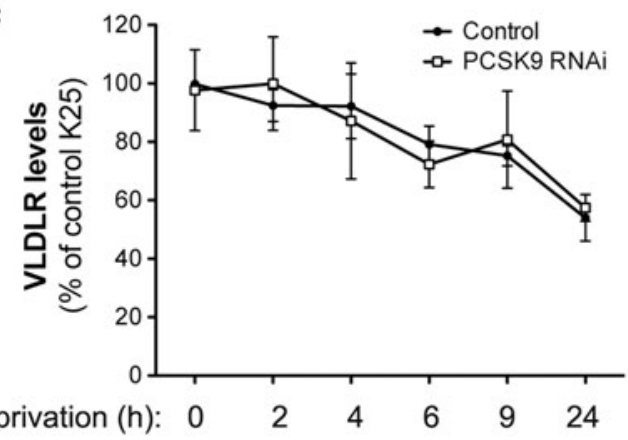

e

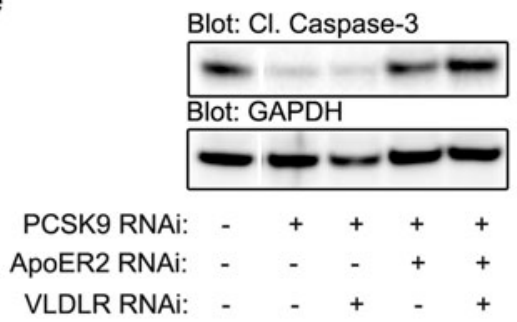

Fig. 3 Potassium deprivation and PCSK9 RNAi alter the levels of VLDLR and ApoER2. a Western blot analysis of VLDLR and ApoER2 levels in whole cell lysates of control CGN with GAPDH as a loading control. b-d Quantitation of VLDLR and ApoER2 levels (control K25 set at $100 \%$ ) in PCSK9 RNAi CGN as normalized to

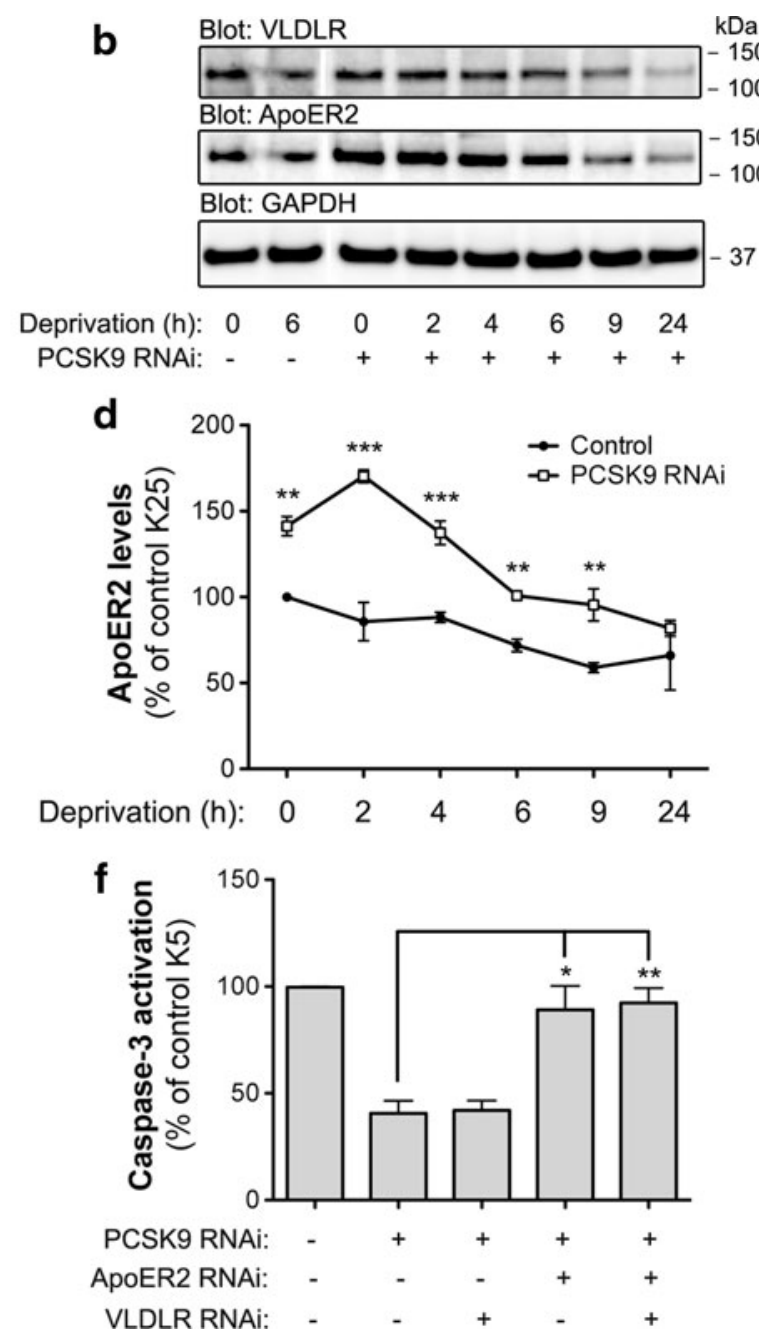

GAPDH levels. e, $\mathbf{f}$ Western blot analysis of caspase-3 activation in CGN transduced with different combinations of PCSK9, ApoER2, and VLDLR RNAi. Data are shown as mean \pm SEM of three or more replicate experiments. In $(\mathbf{d}, \mathbf{f}), * p<0.05, * * p<0.01, * * * p<0.001$

activity level $(8.1 \pm 1.1 \%)$ seen in $\mathrm{K} 25$ control cells $(14.3 \pm 6.1 \%$ for PCSK9 RNAi + SP600125 and $16.7 \pm 3.0 \%$ for PCSK9 RNAi + U0126; Fig. 5a, b). This data suggests that PCSK9 acts in concert with the JNK and ERK signaling pathways to regulate CGN apoptosis.

$\mathrm{PI} 3 \mathrm{~K} / \mathrm{Akt}$ and NF- $\kappa \mathrm{B}$ pathways have previously been shown to be critical for CGN survival [37, 38]. Inhibition of $\mathrm{PI} 3 \mathrm{~K}$ or $\mathrm{NF}-\kappa \mathrm{B}$ in control cells with $\mathrm{K} 5$ deprivation resulted in enhanced caspase- 3 activation (Fig. 5c, d) [38, 39]. When Wrt or SFS were added to PCSK9 RNAi CGN, the anti-apoptotic effects were partially reversed. However, these effects were weaker when compared to the reversal elicited by ApoER2 RNAi (Fig. 3e, f). Altogether, these data suggest that multiple signaling pathways contribute to neuroprotection elicited by PCSK9 RNAi. 
a

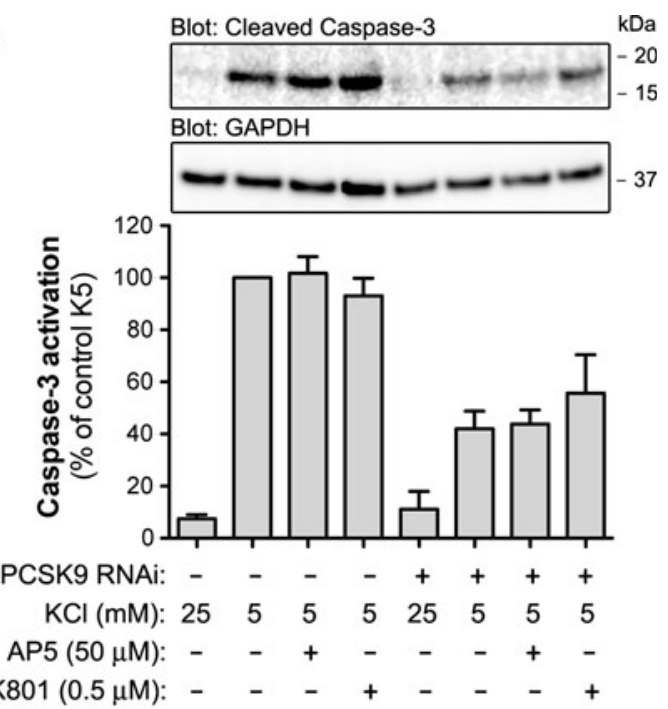

b

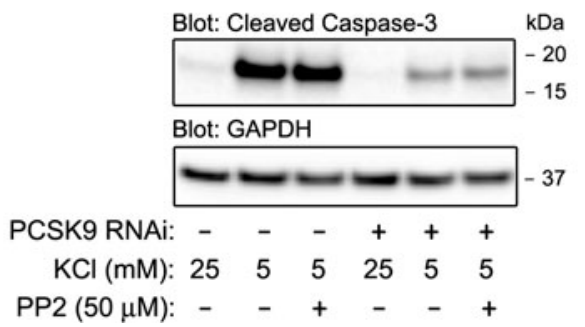

Fig. 4 Blocking NMDA receptor function with antagonists or SFKs with PP2 during potassium deprivation has no effect on neuroprotection elicited by PCSK9 RNAi. a Western blot and quantitation of caspase-3 (control K5 set at $100 \%$ ) activation of control and PCSK9 RNAi CGN with AP5 and MK-801 treatments. b Western blot of caspase-3 activation (control K5 set at $100 \%$ ) of control and PCSK9 RNAi CGN with PP2 treatment. For $\mathbf{a}, \mathbf{b}$ no significant differences were observed in caspase- 3 activation between inhibitor treated and untreated samples

The role of PCSK9 in other models of neuronal apoptosis

To further evaluate the role of PCSK9 in neuronal apoptotic processes, we assessed the effect of PCSK9 RNAi in two other models of neuronal apoptosis: staurosporine (STS)-induced CGN apoptosis and axonal degeneration observed in NGF-deprived DRGN. The broad-spectrum kinase inhibitor STS promotes apoptosis in CGN at $500 \mathrm{nM}$ concentration within $24 \mathrm{~h}$ as observed by caspase-3 activation [40]. No phospho-c-Jun activity was observed at either 6 or $24 \mathrm{~h}$ timepoints, indicating a JNK-independent pathway in induction of apoptosis by STS [40] (Fig. 6b, c). Again, PCSK9 RNAi treatment significantly reduced cell death, and caspase- 3 activation was reduced down to $53.4 \pm 6.8 \%$ at 24 h (Fig. 6a, b). Addition of SP600125 to the media together with STS had no effect on caspase-3 activation with or without PCSK9 RNAi (Fig. 6c), further supporting a JNK-independent mechanism in the STS/
CGN model. This data suggests that PCSK9 can also modulate JNK-independent death pathways.

We also assessed axonal degeneration in a dissociated DRGN culture induced by NGF-withdrawal. Axonal degeneration in DRGN has been previously shown to be partially JNK-dependent [41, 42]. Moreover, DRGN express lipoprotein receptors LDLR and ApoER2 [43]. Dorsal root ganglion neurons grow extensive axonal networks in culture with a relatively small number of neuronal cells and a high number of proliferating glial cells. Counting the number of intact, non-blebbing axons crossing the diagonal of the image was used to score axonal degeneration (Fig. 6d). In control cells, $59.8 \pm 5.8 \%$ of axons remained intact after 48 h NGFdeprivation whereas PCSK9 RNAi increased the intact portion of neurites up to $77.7 \pm 9.3 \%$ (Fig. 6e), an increase of $30 \%$. Altogether, these data suggest that PCSK9 may modulate apoptotic processes involving multiple signaling pathways in different models of neuronal death and degeneration.

\section{Discussion}

Proprotein convertase subtilisin/kexin type 9 has a poorly characterized physiological role in neuronal apoptosis and in the modulation of lipoprotein receptors VLDLR and ApoER2 in the brain. PCSK9 is known to bind to both receptors via the EGF-A repeat of their ectodomains and to target them for degradation, while the expression of PCSK 9 can be induced by apoptotic stimulus together with known apoptosis mediators such as death receptor- 6 and caspase-3 [4, 44]. Recently, PCSK9 was shown to be upregulated and to control LDLR levels in ischemic brain [11]. If PCSK9, with its numerous naturally occurring gainof-function and loss-of-function polymorphisms, also controls ApoER2 and VLDLR levels in the adult brain after apoptotic insults, the possible consequences for neuronal function and integrity may be profound.

In this study, we aimed at preliminary characterization of PCSK9 action in the apoptotic processes of several neuronal death models: activity-dependent and staurosporine-induced CGN apoptosis, as well as NGF deprivation-induced axonal degeneration in dissociated DRGN cultures. We produced lentiviral tools encoding shRNAs targeting PCSK9, ApoER2, and VLDLR. Recently, a similar approach was taken to elucidate the role of PCSK9 in HUVEC apoptosis [21]. We have shown that PCSK9 RNAi significantly reduced cell death in the potassium-deprived or STS-treated CGN, and axonal degeneration in NGF-deprived DRGN, showing that PCSK9 has a strong capacity to modulate all these different neuronal death pathways. 
Fig. 5 Pharmacological profiling of signaling pathways involved in PCSK9 RNAi mediated neuroprotection. a-d Quantitation of caspase-3 activation (control $6 \mathrm{~h} \mathrm{K5}$ set at $100 \%$ ) in control and PCSK9 RNAi CGN treated with inhibitors as normalized to GAPDH levels. Inhibitors for JNK (a; SP600125), ERK (b; U0126), PI3K (c; Wortmannin) and NF- $\kappa \mathrm{B}$ (d; sulfasalazine) pathways were used with and without PCSK9 RNAi. In all pharmacological experiments, cells were pre-treated with inhibitors for $30 \mathrm{~min}$ and equal concentration of inhibitors was added to the deprivation media for $6 \mathrm{~h}$. Data are shown as mean \pm SEM of three or more replicate experiments. $* p<0.05, * * p<0.01$, $* * * p<0.001$
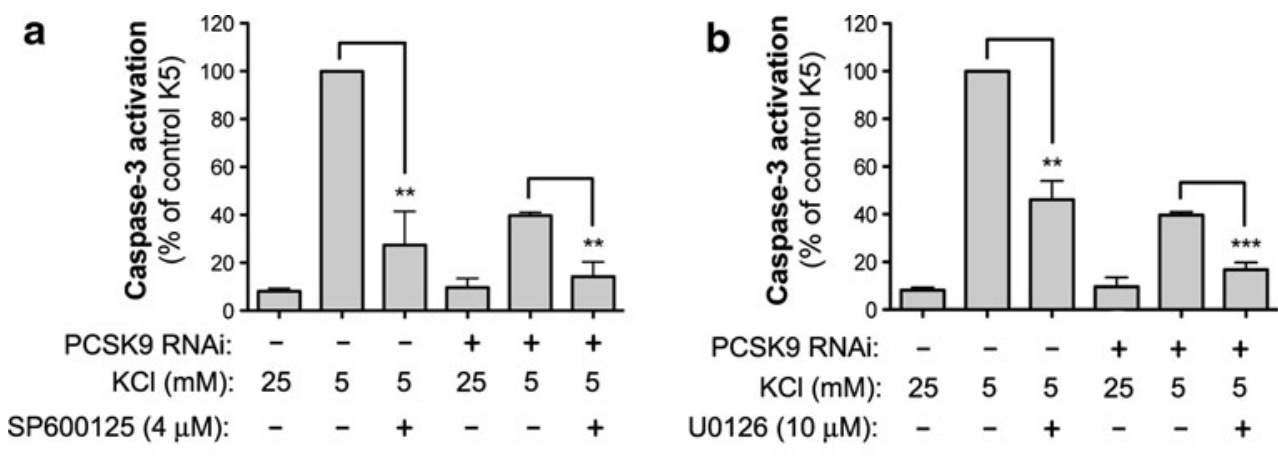

C

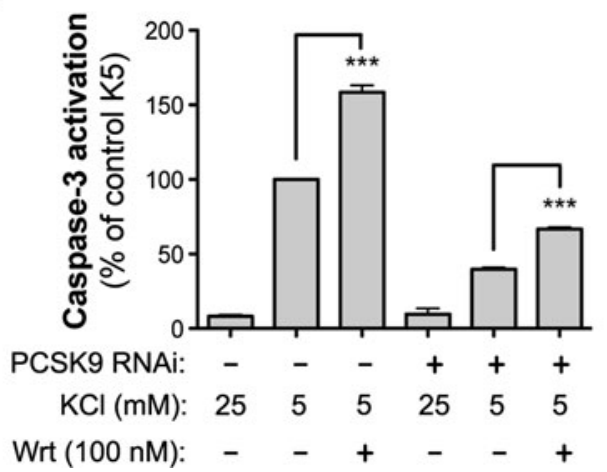

d

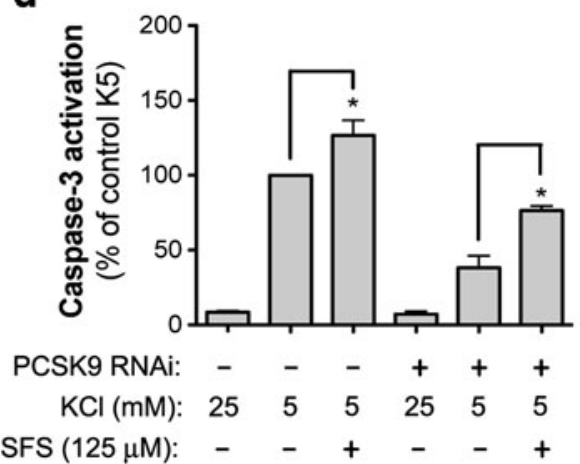

Very low density lipoprotein receptor and ApoER2mediated signaling might provide the basis for the neuroprotection elicited by PCSK9 knockdown. Our results show that, in potassium-deprived CGN, VLDLR and ApoER2 are depleted, and most likely this is related to the upregulation of PCSK9 [4]. This depletion would then reduce the activity of several critical survival signaling pathways. We found that PCSK9 RNAi resulted in elevated levels of ApoER2 with less effect on VLDLR levels. Based on our current data, we cannot address the reason for this differential effect. Both extracellular and intracellular routes for PCSK9-dependent lipoprotein degradative action have been proposed [45, 46]; however, the current study was not designed to address these questions. Moreover, it is possible that PCSK9-independent mechanisms of lipoprotein receptor degradation, mediated, e.g., by ubiquitination [47], may be differentially regulating receptor degradation in stressed and apoptotic neurons. Importantly, only the knockdown of ApoER2 but not of VLDLR was able to completely reverse the anti-apoptotic effect of PCSK9 RNAi, suggesting that ApoER2 is the key mediator of these effects.

There is an emerging view of lipoprotein receptors serving as important players in neuronal survival signaling [48]. Therefore, PCSK9 would be an ideal tool for neurons to quickly downregulate these survival signals to achieve rapid and coordinated apoptosis. This may explain the increased expression of PCSK9 in the postnatal cerebellum that coincides with the extensive developmental apoptosis.
However, although PCSK9 knockdown in zebrafish resulted in severe disorganization of the CNS [18], no gross alterations in the organization of the cortex and cerebellar layers were found in $\mathrm{PCSK}^{-1-}$ mice [49]. If the sole function of PCSK9 in the postnatal mammalian cerebellar neurons is rapid downregulation of ApoER2-dependent survival signaling, it is likely that there are compensatory proapoptotic mechanism(s) that could overcome the lack of PCSK9 to ensure proper cerebellar development. In this regard, it should be noted that PCSK9 might regulate cell death responses differentially in different cell types. In HepG2 cells, PCSK9 gain-of-function mutation (D374Y) was associated with reduced stress responses and cell death [50]. However, these authors also concluded that the PCSK9 function related to apoptosis might be different in hepatocytes and cerebellar neurons.

To explore the signaling pathways involved in PCSK9 RNAi-related neuroprotection, we used a panel of pharmacological inhibitors to block known apoptotic and survival pathways in an attempt to reverse the protective effect. Based on these data, we suggest that PCSK9 may associate with multiple pro- and anti-apoptotic signaling pathways, mostly associated with ApoER2 function. Reduced PCSK9 levels and inhibition of either JNK or ERK pathways had additive anti-apoptotic effects, while inhibition of PI3K or NF- $\kappa$ B partially reversed the antiapoptotic effects of PCSK9 RNAi. Considering the prosurvival effects of physiological NMDA currents and the potent NMDA receptor enhancing effects of ApoER2 

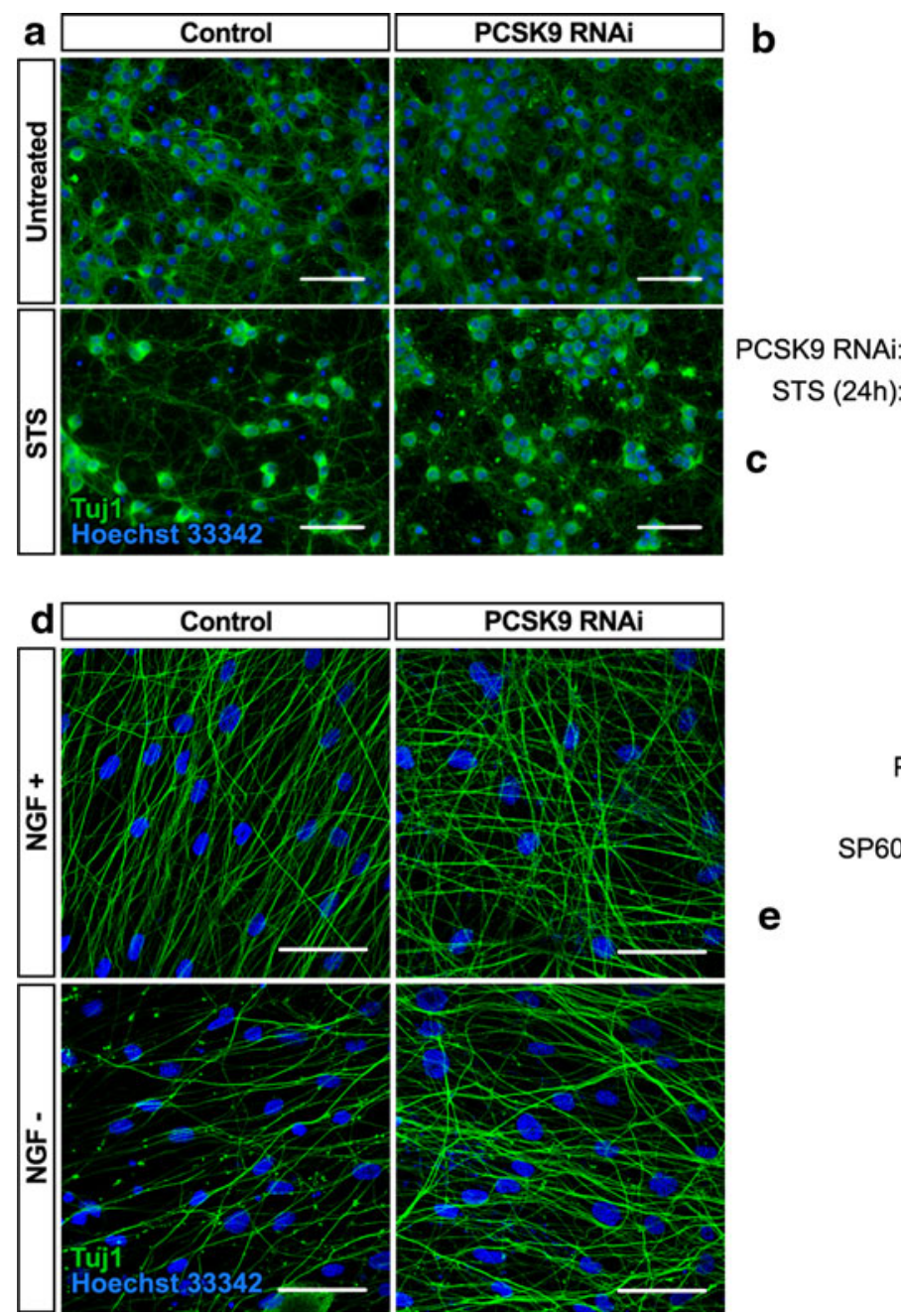

Fig. 6 PCSK9 RNAi neuroprotection in staurosporine and NGFdeprivation induced apoptosis. a Representative IF images showing nuclei (Hoechst 33342, blue) and neuron-specific $\beta$-tubulin-III (Tuj1, green) in control and PCSK9 RNAi CGN with and without $24 \mathrm{~h}$ STStreatment. b Western blot analysis of caspase-3 and c-Jun activation and quantitation (control $24 \mathrm{~h}$ STS set at $100 \%$ ) normalized to GAPDH. c Western blot analysis of caspase-3 and c-Jun activation after $6 \mathrm{~h}$ co-treatment with STS and SP600125. d Confocal images of

signaling [34, 51], it was surprising that interfering with NMDA receptor function or SFK activity had no effect on the anti-apoptotic effects of PCSK9 RNAi.

It is plausible that the upregulation of PCSK9 in the degenerating, aging, or otherwise traumatized brain tissue could compromise neuronal survival by exploiting the mechanisms identified in this work. Moreover, ApoE plays a critical role in the pathophysiology of Alzheimer's disease (AD) [52], and altered lipoprotein receptor signaling may contribute to disease progression by modulating, e.g., $\beta$-amyloid peptide $(\mathrm{A} \beta)$-induced synaptic dysfunction [31] or neuronal cell death in general [15]. In this regard, it is interesting to note that PCSK9 was recently reported to be upregulated in the dentate gyrus following ischaemic
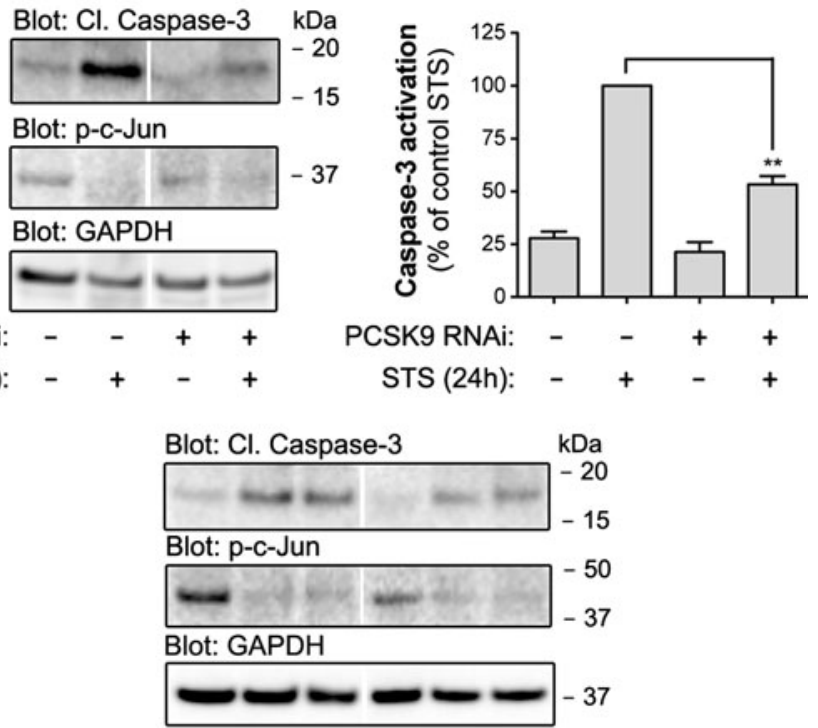

$\begin{array}{rrrrrrr}\text { PCSK9 RNAi: } & - & - & - & + & + & + \\ \text { STS }(6 \mathrm{~h}): & - & + & + & - & + & + \\ \text { P600125 }(4 \mu \mathrm{M}): & - & - & + & - & - & +\end{array}$

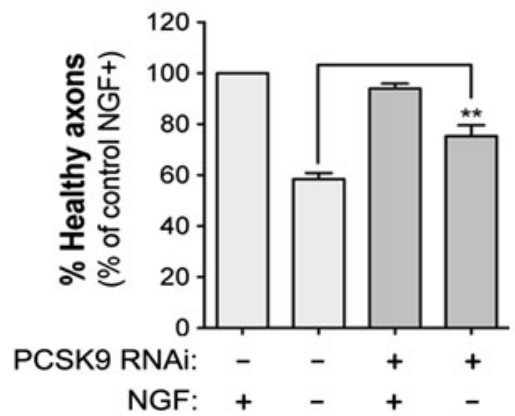

DRGN cultures showing extensive axonal networks (Tuj1, green) and high number of glial nuclei (Hoechst 33342, blue) with and without NGF. e The percentage of healthy axons (control NGF + set at $100 \%$ ) counted to cross a diagonal line drawn over the image. Six or more images were scored per each group in five separate experiments. For a, d scale bars $50 \mu \mathrm{m}$. Data are shown as mean \pm SEM of three or more replicate experiments. In $(\mathbf{b}, \mathbf{e}), * * p<0.01$

stroke [11]. To date, only one published study exists addressing the potential genetic link of PCSK9 to neurodegenerative diseases and it found no association of two PCSK9 polymorphisms to sporadic AD in a Japanese cohort [53]. Given the important role of apoptosis in both developing and degenerating nervous system, further studies are required to understand if, how, and when PCSK9 is upregulated in the aging and degenerating brain, but also if the common PCSK9 polymorphisms are associated with neuronal disease. There is increasing interest towards developing ApoE-based therapeutics for AD [54], and PCSK9 inhibitors for hypercholesterolemia [55]. Thus, more detailed understanding of the potential roles of PCSK9 in regulation of neuronal cell death will support the 
development of safe and efficacious therapeutic strategies targeting ApoE and lipoprotein receptor function.

Acknowledgments This study was supported by grants from the Academy of Finland (grant numbers 281081 and 126889), Sigrid Jusélius Foundation, Biocentrum Helsinki, Finnish Cultural Foundation and Antti and Jenny Wihuri Foundation. The research leading to these results has received funding from the European Union's Seventh Framework Programme (FP7/2007-2011) under grant agreement No. 206918 and Academy of Finland program 11186236 (Finnish Centre of Excellence Program 2008-2013). K.K. and H.J.H. designed research; K.K., P.M., and K.M. performed research; K.K., U.A., and H.J.H. analyzed data; and K.K., U.A., and H.J.H. wrote the paper. H.J.H is a cofounder, employee and shareholder of Hermo Pharma Ltd. Other authors declare that they have no conflict of interest.

\section{References}

1. Yuan J, Yankner BA (2000) Apoptosis in the nervous system. Nature 407:802-809

2. Seidah NG, Benjannet $S$, Wickham L, Marcinkiewicz J, Jasmin SB, Stifani S, Basak A, Prat A, Chretien M (2003) The secretory proprotein convertase neural apoptosis-regulated convertase 1 (NARC-1): liver regeneration and neuronal differentiation. Proc Natl Acad Sci USA 100:928-933

3. Abifadel M, Varret M, Rabes JP, Allard D, Ouguerram K, Devillers M, Cruaud C, Benjannet S, Wickham L, Erlich D, Derre A, Villeger L, Farnier M, Beucler I, Bruckert E, Chambaz J, Chanu B, Lecerf JM, Luc G, Moulin P, Weissenbach J, Prat A, Krempf M, Junien C, Seidah NG, Boileau C (2003) Mutations in PCSK9 cause autosomal dominant hypercholesterolemia. Nat Genet 34:154-156

4. Bingham B, Shen R, Kotnis S, Lo CF, Ozenberger BA, Ghosh N, Kennedy JD, Jacobsen JS, Grenier JM, DiStefano PS, Chiang LW, Wood A (2006) Proapoptotic effects of NARC 1 (=PCSK9), the gene encoding a novel serine proteinase. Cytometry A 69:1123-1131

5. Li J, Tumanut C, Gavigan JA, Huang WJ, Hampton EN, Tumanut R, Suen KF, Trauger JW, Spraggon G, Lesley SA, Liau G, Yowe D, Harris JL (2007) Secreted PCSK9 promotes LDL receptor degradation independently of proteolytic activity. Biochem J 406:203-207

6. Shan L, Pang L, Zhang R, Murgolo NJ, Lan H, Hedrick JA (2008) PCSK9 binds to multiple receptors and can be functionally inhibited by an EGF-A peptide. Biochem Biophys Res Commun 375:69-73

7. Poirier S, Mayer G, Benjannet S, Bergeron E, Marcinkiewicz J, Nassoury N, Mayer H, Nimpf J, Prat A, Seidah NG (2008) The proprotein convertase PCSK9 induces the degradation of low density lipoprotein receptor (LDLR) and its closest family members VLDLR and ApoER2. J Biol Chem 283:2363-2372

8. Yamamoto T, Lu C, Ryan RO (2011) A two-step binding model of PCSK9 interaction with the low density lipoprotein receptor. J Biol Chem 286:5464-5470

9. Benjannet S, Rhainds D, Essalmani R, Mayne J, Wickham L, Jin W, Asselin MC, Hamelin J, Varret M, Allard D, Trillard M, Abifadel M, Tebon A, Attie AD, Rader DJ, Boileau C, Brissette L, Chretien M, Prat A, Seidah NG (2004) NARC-1/PCSK9 and its natural mutants: zymogen cleavage and effects on the low density lipoprotein (LDL) receptor and LDL cholesterol. J Biol Chem 279:48865-48875

10. Liu M, Wu G, Baysarowich J, Kavana M, Addona GH, Bierilo KK, Mudgett JS, Pavlovic G, Sitlani A, Renger JJ, Hubbard BK,
Fisher TS, Zerbinatti CV (2010) PCSK9 is not involved in the degradation of LDL receptors and BACE1 in the adult mouse brain. J Lipid Res 51:2611-2618

11. Rousselet E, Marcinkiewicz J, Kriz J, Zhou A, Hatten ME, Prat A, Seidah NG (2011) PCSK9 reduces the protein levels of the LDL receptor in mouse brain during development and after ischemic stroke. J Lipid Res 52:1383-1391

12. Reddy SS, Connor TE, Weeber EJ, Rebeck W (2011) Similarities and differences in structure, expression, and functions of VLDLR and ApoER2. Mol Neurodegener 6:30

13. Trommsdorff M, Gotthardt M, Hiesberger T, Shelton J, Stockinger W, Nimpf J, Hammer RE, Richardson JA, Herz J (1999) Reeler/disabled-like disruption of neuronal migration in knockout mice lacking the VLDL receptor and ApoE receptor 2. Cell 97:689-701

14. Larouche M, Beffert U, Herz J, Hawkes R (2008) The Reelin receptors Apoer2 and Vldlr coordinate the patterning of Purkinje cell topography in the developing mouse cerebellum. PLoS ONE 3:e1653

15. Beffert U, Nematollah Farsian F, Masiulis I, Hammer RE, Yoon SO, Giehl KM, Herz J (2006) ApoE receptor 2 controls neuronal survival in the adult brain. Curr Biol 16:2446-2452

16. Andersen OM, Benhayon D, Curran T, Willnow TE (2003) Differential binding of ligands to the apolipoprotein E receptor 2. Biochemistry 42:9355-9364

17. Sinagra M, Verrier D, Frankova D, Korwek KM, Blahos J, Weeber EJ, Manzoni OJ, Chavis P (2005) Reelin, very-lowdensity lipoprotein receptor, and apolipoprotein E receptor 2 control somatic NMDA receptor composition during hippocampal maturation in vitro. J Neurosci 25:6127-6136

18. Poirier S, Prat A, Marcinkiewicz E, Paquin J, Chitramuthu BP, Baranowski D, Cadieux B, Bennett HP, Seidah NG (2006) Implication of the proprotein convertase NARC-1/PCSK9 in the development of the nervous system. J Neurochem 98:838-850

19. Rashid S, Curtis DE, Garuti R, Anderson NN, Bashmakov Y, Ho YK, Hammer RE, Moon YA, Horton JD (2005) Decreased plasma cholesterol and hypersensitivity to statins in mice lacking Pcsk9. Proc Natl Acad Sci USA 102:5374-5379

20. Lopez D (2008) Inhibition of PCSK9 as a novel strategy for the treatment of hypercholesterolemia. Drug News Perspect $21: 323-330$

21. Wu CY, Tang ZH, Jiang L, Li XF, Jiang ZS and Liu LS (2012) PCSK9 siRNA inhibits HUVEC apoptosis induced by ox-LDL via $\mathrm{Bcl} / \mathrm{Bax}$-caspase9-caspase3 pathway. Mol Cell Biochem 359:347-358

22. Miller TM, Johnson EMJ (1996) Metabolic and genetic analyses of apoptosis in potassium/serum-deprived rat cerebellar granule cells. J Neurosci 16:7487-7495

23. Contestabile A (2002) Cerebellar granule cells as a model to study mechanisms of neuronal apoptosis or survival in vivo and in vitro. Cerebellum 1:41-55

24. Yan GM, Ni B, Weller M, Wood KA, Paul SM (1994) Depolarization or glutamate receptor activation blocks apoptotic cell death of cultured cerebellar granule neurons. Brain Res 656:43-51

25. Kramer D, Minichiello L (2010) Cell culture of primary cerebellar granule cells. Methods Mol Biol 633:233-239

26. Coffey ET, Smiciene G, Hongisto V, Cao J, Brecht S, Herdegen T, Courtney MJ (2002) c-Jun N-terminal protein kinase (JNK) 2/3 is specifically activated by stress, mediating c-Jun activation, in the presence of constitutive JNK1 activity in cerebellar neurons. J Neurosci 22:4335-4345

27. Caballero-Benitez A, Moran J (2003) Caspase activation pathways induced by staurosporine and low potassium: role of caspase-2. J Neurosci Res 71:383-396 
28. Villalba M, Bockaert J, Journot L (1997) Concomitant induction of apoptosis and necrosis in cerebellar granule cells following serum and potassium withdrawal. NeuroReport 8:981-985

29. Hoe HS, Harris DC, Rebeck GW (2005) Multiple pathways of apolipoprotein $\mathrm{E}$ signaling in primary neurons. J Neurochem 93:145-155

30. Roubtsova A, Munkonda MN, Awan Z, Marcinkiewicz J, Chamberland A, Lazure C, Cianflone K, Seidah NG, Prat A (2011) Circulating proprotein convertase subtilisin/kexin 9 (PCSK9) regulates VLDLR protein and triglyceride accumulation in visceral adipose tissue. Arterioscler Thromb Vasc Biol 31:785-791

31. Durakoglugil MS, Chen Y, White CL, Kavalali ET, Herz J (2009) Reelin signaling antagonizes beta-amyloid at the synapse. Proc Natl Acad Sci USA 106:15938-15943

32. Hardingham GE (2009) Coupling of the NMDA receptor to neuroprotective and neurodestructive events. Biochem Soc Trans 37:1147-1160

33. Xifro X, Falluel-Morel A, Minano A, Aubert N, Fado R, Malagelada C, Vaudry D, Vaudry H, Gonzalez B, RodriguezAlvarez J (2006) $N$-methyl-D-aspartate blocks activation of JNK and mitochondrial apoptotic pathway induced by potassium deprivation in cerebellar granule cells. J Biol Chem 281: 6801-6812

34. Chen Y, Beffert U, Ertunc M, Tang TS, Kavalali ET, Bezprozvanny I, Herz J (2005) Reelin modulates NMDA receptor activity in cortical neurons. J Neurosci 25:8209-8216

35. Yamagishi S, Matsumoto T, Numakawa T, Yokomaku D, Adachi N, Hatanaka H, Yamada M, Shimoke K, Ikeuchi T (2005) ERK1/ 2 are involved in low potassium-induced apoptotic signaling downstream of ASK1-p38 MAPK pathway in cultured cerebellar granule neurons. Brain Res 1038:223-230

36. Yeste-Velasco M, Folch J, Casadesus G, Smith MA, Pallas M, Camins A (2009) Neuroprotection by c-Jun NH2-terminal kinase inhibitor SP600125 against potassium deprivation-induced apoptosis involves the Akt pathway and inhibition of cell cycle reentry. Neuroscience 159:1135-1147

37. Bhakar AL, Tannis LL, Zeindler C, Russo MP, Jobin C, Park DS, MacPherson S, Barker PA (2002) Constitutive nuclear factorkappa B activity is required for central neuron survival. J Neurosci 22:8466-8475

38. Vazquez de la Torre A, Junyent F, Folch J, Pelegri C, Vilaplana J, Auladell C, Beas-Zarate C, Pallas M, Camins A, Verdaguer E (2011) Study of the pathways involved in apoptosis induced by PI3K inhibition in cerebellar granule neurons. Neurochem Int 59:159-167

39. Kovacs AD, Chakraborty-Sett S, Ramirez SH, Sniderhan LF, Williamson AL, Maggirwar SB (2004) Mechanism of NF-kappaB inactivation induced by survival signal withdrawal in cerebellar granule neurons. Eur J Neurosci 20:345-352

40. Ramiro-Cortes Y, Moran J (2009) Role of oxidative stress and JNK pathway in apoptotic death induced by potassium deprivation and staurosporine in cerebellar granule neurons. Neurochem Int 55:581-592

41. Harding TC, Xue L, Bienemann A, Haywood D, Dickens M, Tolkovsky AM, Uney JB (2001) Inhibition of JNK by overexpression of the JNL binding domain of JIP-1 prevents apoptosis in sympathetic neurons. J Biol Chem 276:4531-4534

42. Eilers A, Whitfield J, Shah B, Spadoni C, Desmond H, Ham J (2001) Direct inhibition of c-Jun N-terminal kinase in sympathetic neurones prevents c-jun promoter activation and NGF withdrawal-induced death. J Neurochem 76:1439-1454

43. Kosacka J, Schroder T, Bechmann I, Kloting N, Nowicki M, Mittag A, Gericke M, Spanel-Borowski K, Bluher M (2011) PACAP up-regulates the expression of apolipoprotein D in 3T3L1 adipocytes. DRG/3T3-L1 co-cultures study. Neurosci Res 69:8-16

44. Chiang LW, Grenier JM, Ettwiller L, Jenkins LP, Ficenec D, Martin J, Jin F, DiStefano PS, Wood A (2001) An orchestrated gene expression component of neuronal programmed cell death revealed by cDNA array analysis. Proc Natl Acad Sci USA 98:2814-2819

45. Qian YW, Schmidt RJ, Zhang Y, Chu S, Lin A, Wang H, Wang X, Beyer TP, Bensch WR, Li W, Ehsani ME, Lu D, Konrad RJ, Eacho PI, Moller DE, Karathanasis SK, Cao G (2007) Secreted PCSK9 downregulates low density lipoprotein receptor through receptor-mediated endocytosis. J Lipid Res 48:1488-1498

46. Poirier S, Mayer G, Poupon V, McPherson PS, Desjardins R, Ly K, Asselin MC, Day R, Duclos FJ, Witmer M, Parker R, Prat A, Seidah NG (2009) Dissection of the endogenous cellular pathways of PCSK9-induced low density lipoprotein receptor degradation: evidence for an intracellular route. J Biol Chem 284:28856-28864

47. Hong C, Duit S, Jalonen P, Out R, Scheer L, Sorrentino V, Boyadjian R, Rodenburg KW, Foley E, Korhonen L, Lindholm D, Nimpf J, van Berkel TJ, Tontonoz P, Zelcer N (2010) The E3 ubiquitin ligase IDOL induces the degradation of the low density lipoprotein receptor family members VLDLR and ApoER2. J Biol Chem 285:19720-19726

48. Herz J, Chen Y (2006) Reelin, lipoprotein receptors and synaptic plasticity. Nat Rev Neurosci 7:850-859

49. Seidah NG, Mayer G, Zaid A, Rousselet E, Nassoury N, Poirier S, Essalmani R, Prat A (2008) The activation and physiological functions of the proprotein convertases. Int J Biochem Cell Biol 40:1111-1125

50. Ranheim T, Mattingsdal M, Lindvall JM, Holla OL, Berge KE, Kulseth MA, Leren TP (2008) Genome-wide expression analysis of cells expressing gain of function mutant D374Y-PCSK9. J Cell Physiol 217:459-467

51. Monti B, Marri L, Contestabile A (2002) NMDA receptor-dependent CREB activation in survival of cerebellar granule cells during in vivo and in vitro development. Eur J Neurosci 16:1490-1498

52. Kim J, Basak JM, Holtzman DM (2009) The role of apolipoprotein E in Alzheimer's disease. Neuron 63:287-303

53. Shibata N, Ohnuma T, Higashi S, Higashi M, Usui C, Ohkubo T, Watanabe T, Kawashima R, Kitajima A, Ueki A, Nagao M, Arai H (2005) No genetic association between PCSK9 polymorphisms and Alzheimer's disease and plasma cholesterol level in Japanese patients. Psychiatr Genet 15:239

54. Cramer PE, Cirrito JR, Wesson DW, Lee CY, Karlo JC, Zinn AE, Casali BT, Restivo JL, Goebel WD, James MJ, Brunden KR, Wilson DA and Landreth GE (2012) ApoE-directed therapeutics rapidly clear beta-amyloid and reverse deficits in $\mathrm{AD}$ mouse models. Science 335:1503-1506

55. Liang H, Chaparro-Riggers J, Strop P, Geng T, Sutton JE, Tsai D, Bai L, Abdiche Y, Dilley J, Yu J, Wu S, Chin SM, Lee NA, Rossi A, Lin JC, Rajpal A, Pons J, Shelton DL (2012) Proprotein convertase substilisin/kexin type 9 antagonism reduces lowdensity lipoprotein cholesterol in statin-treated hypercholesterolemic nonhuman primates. J Pharmacol Exp Ther 340:228-236 